\title{
REFLEXÕES SOBRE UM PROJETO DE EXTENSÃO EM LÍNGUA FRANCESA: AMPLIANDO SABERES LINGUÍSTICOS, CULTURAIS E REDIMENSIONANDO A FORMAÇÃO DE PROFESSORES DE LÍNGUA.
}

\author{
Sandra Helena Gurgel Dantas de MEDEIROS \\ Universidade Federal da Paraíba
}

RESUMO

Conscientes de que projetos de extensão no curso de Licenciatura em Letras Estrangeiras desempenham a função de possibilitar ao aluno-professor em formação mais um momento para reflexão e desenvolvimento de suas práticas didático-pedagógicas, apresentaremos a

experiência com o projeto de extensão Língua e cultura francesas para as comunidades acadêmica e externa, vivenciado no decorrer do ano de 2015 na Universidade Federal da Paraíba. O projeto apresentado teve como objetivo oferecer aulas de língua e cultura francesas numa perspectiva intercultural. Abordaremos os saberes adquiridos pelo aluno-professor em formação e as dificuldades encontradas na sala de aula ao ministrar os conteúdos propostos. Além disso, será feita uma descrição das especificidades e objetivos dos alunos participantes do projeto e suas consequências na realização de constantes reflexões do aluno-professor em formação quanto a sua prática didático-pedagógica consolidando os conteúdos curriculares trabalhados na academia e união com a prática. Primeiramente, contextualizaremos o projeto, sua justificativa e objetivo, o perfil sociocultural do público participante e metodologia empregada. Como veremos, propomos uma abordagem interculturalista na aula de língua estrangeira, para isto, fizemos embasamento teórico na leitura de autores que encontram na perspectiva intercultural mais um instrumento no processo de aquisição de uma língua (DE CARLO, 1998, ZARATE, 1986, CHIANCA, 2007). Em seguida, elencamos e refletimos sobre os elementos que contribuíram para o desenvolvimento profissional do aluno-professor de língua em formação inicial. A análise dos saberes docentes adquiridos e o ofício de professor efetivou-se com leituras de autores como LESSARD, 2008, TARDIF, 2000 bem como embasamento teórico pautado na didática das línguas estrangeiras MARTINEZ, 2008.

PALAVRAS CHAVE: Extensão; formação de professor; ensino/aprendizagem de FLE; perspectiva intercultural.

RÉSUMÉ : Nous sommes convainqus que les projets de Extensão dans le cours de licence en lettres/langues étrangères ont la fonction, entre autres, d'offrir à l'étudientprofesseur en formation des moments favorables à la reflexion et le développement de ses pratiques didactico-pédagogiques. Cela dit, dans ce travail, nous tenons à presenter notre expérience à partir du projet de Extensão intitulé Langue et culture françaises aux communautés académique et extérieure dans une perspective interculturelle, réalisé en 2015 à l'Université Fédérale de Paraiba. Nous presenterons également les savoirs 
acquis par l'étudient-professeur en formation et les difficultés trouvées dans la salle de classe lors de la transmission des contenus proposés. En outre, nous ferons une description des spécificités et des objectifs des élèves participants du projet et les conséquences dans la realisation de reflexions constantes entreprises par l'étudientprofesseur en formation à propos de sa pratique didactico-pédagogique tout en consolidant les contenus curriculaires étudiés pendant le cours et l'union de ceux-ci avec la pratique. Tout d'abord, nous présenterons le contexte du projet, sa motivation, son objectif, le profil socioculturel des élèves participants et méthodologie utilisée. Nous proposerons une approche interculturelle dans les cours de langue étrangère et pour cela, nous nous sommes appuyés sur les lectures des théoriques qui sont d'avis que la perspective interculturelle signifie encore un moyen important dans le procesus d'enseignements/apprentissage d'une langue (DE CARLO, 1998, ZARATE, 1986, CHIANCA, 2007). En suite, nous dresserons une liste d'éléments considérables dans la formation du professeur de langue et des reflexions sur ceux qui ont contribués au dévéloppement professionnel de l'étudient-professeur en formation initiale. Les lectures des auteurs tels que LESSARD, 2008, TARDIF, 200 et MARTINEZ seront la source de l'analyse des savoirs sur l'enseignement acquis et le métier d'enseignant ainsi que la base théorique de notre recherche sur la didactique des langues étrangères.

MOTS-CLÉS : Extensão; formation d'enseignant; enseignement/apprentissage de FLE; perspective interculturelle.

\title{
Introdução
}

A docência requer conhecimentos que vão desde a compreensão das disciplinas, dos currículos, da ação pedagógica até a construção de saberes, elementos estes que podem ser apreendidos pelo aluno-professor em formação, através da prática docente em projetos de Extensão.

\begin{abstract}
“(...) toda ação de extensão deverá estar vinculada ao processo de formação de pessoas e de geração de conhecimento, tendo o aluno como protagonista de sua formação técnica para obtenção de competências necessárias à atuação profissional, e de sua formação cidadã (...) assumindo uma visão transformadora e um compromisso" (BRASIL, 2007, p. 18).
\end{abstract}

Portanto, atuar na extensão, propicia, entre outros, a solidez do fazer didático-pedagógico ao docente em formação. Esta experiência de atividade endereçada, onde ele mesmo é ator protagonista do ensino aprendizagem, leva-o à constante reflexão sobre o ofício de ser professor, através da experimentação. Segundo PEREZ 2014, parece-nos pertinente enfatizar, no entanto, que, para que os alunosprofessores possam, de fato, ter experiências significativas, é necessário que os cursos de formação se preocupem em unir a teoria e a prática (PEREZ, 2014, p. 181).

Nessa perspectiva, este trabalho apresenta, como objetivo principal, apontar e refletir sobre aspectos que integraram e contribuíram na formação do aluno-professor 
de língua, a partir do projeto de extensão vinculado ao Programa de bolsas da Extensão - PROBEX-UFPB, realizado no ano letivo de 2015, intitulado : Língua e cultura francesas para as comunidades acadêmica e externa.

\section{Contextualizando o projeto:}

O projeto de Extensão, Língua e cultura francesas para as comunidades acadêmica e externa está vinculado ao Programa de Bolsas de Extensão - PROBEX, Edição 2015. Vejamos o que reza o Edital PROBEX 2015:

Esse programa se constitui em uma das estratégias da política de extensão da UFPB, que prioriza a formação acadêmica e cidadã do seu corpo discente através de ações identificadas com as necessidades e as demandas da sociedade paraibana, no sentido de promover o desenvolvimento socioeconômico e cultural a partir de um trabalho conjunto com as comunidades e grupos envolvidos. O PROBEX é mantido com recursos próprios da Universidade, previstos no seu orçamento, e tem o propósito de contribuir para a formação acadêmica dos estudantes dos cursos de graduação e das escolas técnicas, a partir da experiência em ações de extensão universitária. A COPAC é responsável pela seleção de projetos e autorização das bolsas, conforme sua base normativa que está fixada nas Resoluções do CONSEPE $\mathrm{N}^{\circ} \mathrm{s}$ 61/2014 e $N^{\circ}$ 76/1997. Diante do exposto, faz-se necessária a colaboração das unidades acadêmicas e administrativas da UFPB e de parceiros externos, com outras formas de apoio e recursos para contribuir na execução do Programa de Bolsas - PROBEX 2015. (EDITAL-PROBEX-2015, UFPB)

O referido projeto teve início em maio de 2015 e conclusão em dezembro do mesmo ano. As aulas seguiam o nível A1, segundo o Quadro Comum Europeu de Referência para as Línguas e eram realizadas em dois encontros semanais de $2 \mathrm{~h}$ ministradas na própria Universidade Federal da Paraíba.

\section{Contexto social da formação da aluna-professora do projeto}

A aluna-professora do projeto foi selecionada para a bolsa segundo os critérios de seleção exigidos pelo Programa. Alfabetizada na França (Rouen) é aluna do $9^{\circ}$ período de licenciatura em Letras francês da UFPB e bacharel em Direito também por esta Universidade. Durante todo o projeto, a aluna-professora preparou e ministrou as aulas sob orientação da coordenadora do projeto (nota de rodapé).

\section{Justificativa e objetivo do projeto}


A consciência da importância e do valor conferidos ao conhecimento da língua francesa deve-se, também à ampliação de convênios firmados entre a UFPB e outras Instituições francófonas de Ensino Superior. Além disso, o Brasil está promovendo uma política de fortalecimento dos estudos de outras línguas visando à internacionalização do país. O novo Programa do MEC, Idiomas sem Fronteiras, prevê o contato de alunos com a língua e a cultura de vários países, inclusive de língua francesa. Assim, faz-se necessária a mobilização de professores de língua estrangeira a fim de desenvolverem tarefas específicas ligadas ao ensino aprendizagem de línguas. Segundo D’OLIVEIRA, a língua francesa continua a ser uma língua internacional, não requer tanto esforço para um brasileiro e permanece uma língua cuja produção cultural e técnica interessa ao Brasil. Faz sentido ter-lhe o domínio não somente da gramática, mas também da cultura visto que há, nesta língua, vasta produção cultural no meio acadêmico, filosófico, artístico e tecnológico. Além disso, o francês é o idioma da gastronomia, da arte e da moda, falado em 56 países como França, Canadá, Camarões, Suíça, Costa do marfim, Bélgica, entre outros. É também o idioma oficial dos jogos olímpicos de 2016. Portanto, faz sentido que estudantes a comunidade apresentem um nível considerável no conhecimento em Língua e Cultura Francesas. Dito isto, este projeto teve como objetivo oferecer aulas de língua e cultura francesas para as comunidades acadêmica e externa através de uma perspectiva intercultural.

\section{Perfil sociocultural e objetivos dos alunos participantes do projeto}

A sala de aula era composta de 25 alunos, com faixas etárias entre 17 e 57 anos, portanto, bastante heterogênea. Quanto ao nível de escolaridade, todos os alunos tinham o Ensino Médio completo, e a sua maioria já no nível Superior (em andamento ou concluído). Eram jornalistas, engenheiros, sociólogos, professores da UFPB, auxiliares de contabilidade, funcionários públicos, atrizes, recepcionistas e estudantes universitários da UFPB nos seus mais variados cursos.

Através da análise do conteúdo de um questionário aplicado aos alunos participantes, no primeiro dia de aula, com o objetivo, entre outros, de conhecer suas expectativas ao optarem por aprender francês, constatamos diferentes objetivos quanto à aprendizagem da língua e cultura francesa. Dentre os quais, enriquecer o currículo acadêmico e profissional, a pesquisa científica, a comunicação e a cultura, além do turismo, proficiência, entre outros. Verificamos que a maioria dos alunos inscritos nunca teve contato com a língua e cultura francesa e, os que já tiveram algum contato, era de curta duração ou há muito tempo.

Mediante estes alunos heterogêneos, formulamos questões norteadoras que nos conduziram à reflexão do nosso fazer pedagógico, tanto na preparação das aulas para o projeto, como na abordagem dos conteúdos na sala de aula. Portanto, como conciliar o ensino de língua e as transformações de uma sociedade, cada vez mais complexa, composta de alunos heterogêneos e com objetivos mais diversificados em um contexto no qual há um crescente fluxo de contato de populações de diversas origens culturais? Quais elementos entram na preparação de uma aula de língua cujos objetivos devem contemplar esta realidade? Quais as bases do conhecimento entram em campo 
Através da metodologia empregada no Projeto procuramos conduzir nossa didática (prática) a redefinir os recursos de ensino-aprendizagem, transformando percursos de carreira e identidade profissional do aluno-professor, refletindo, também, sobre o papel do professor (formador) e dos próprios alunos participantes, na construção dos seus objetivos. Nessa perspectiva, traçamos um caminho metodológico onde realizamos reflexões sobre a prática na Extensão buscando possíveis respostas às questões apresentadas anteriormente.

Assim, conforme já o dissemos, a aluna-professora em formação, ministrava aulas com duração de $2 \mathrm{~h}$ por semana, na própria UFPB. Os recursos utilizados foram o livro didático Mobile Al Méthode de Français-Didier, 2012 (composto por livro didático, um CD de áudio e um DVD vídeo), o áudio para reprodução de diálogos do livro como também de músicas, e o projetor, possibilitando a visualização de fotos, clipes assim como de filmes. Em relação à cultura na sala de aula temas como a gastronomia francesa, letras de músicas, com cantigas de roda (comptines). Convidamos alunos francófonos para apresentarem aspectos de sua cultura observando os accents (sotaques) diferentes, além de outras atividades. Saberes linguísticos e socioculturais

Vários foram os gêneros textuais que serviram de recursos didático-pedagógicos na elaboração das aulas. Citemos, por exemplo, o livro do aluno. $\mathrm{O}$ aluno-professor em formação constata que esta escolha é primordial uma vez que delineia as perspectivas pedagógicas e a abordagem sociológica assumida permitindo que o aluno se engaje no processo de ensino-aprendizagem da língua estrangeira. Além do livro didático, utilizamos também "documentos autênticos" como ferramentas em práticas didáticopedagógicas. Segundo GALISSON e COSTE (1976 apud MEDEIROS, 2010, p. 56), "autêntico" em didática do francês língua estrangeira (FLE) é:

Todo documento, sonoro ou escrito, que não seja elaborado propositalmente para a classe ou para o estudo da língua, mas para responder a uma função de comunicação, de informação, ou de expressão linguística real (...) um fragmento gravado de conversação, um artigo de jornal, uma página de Balzac, um poema... são documentos autênticos (1976 apud MEDEIROS, 2010, p. 56, tradução nossa) $)^{1}$.

Os documentos autênticos são produzidos por nativos, sem nenhum objetivo didático-pedagógico. No entanto, estes gêneros textuais podem ser "didatizados", empregados nos livros didáticos com finalidades no ensino-aprendizagem. Podemos elencar, como exemplo de documentos autênticos: folders de hotel, de viagem, horários

\footnotetext{
${ }^{1}$ Tout document, sonore ou écrit, qui n'a pas été conçu expressément pour la classe ou pour l'étude de la langue, mais pour répondre à une fonction de communication, d'information, ou d'expression linguistique réelle. (...) Un extrait de conversation enregistré, un article de journal, une page de Balzac, un poème... sont des documents authentiques.
} 
de trem, mapa da cidade, letras de música, publicidades, texto de jornal, texto literário, histórias em quadrinhos, entre vários outros.

Ao trabalharmos com estes recursos percebemos que os alunos participantes traziam consigo algum conhecimento da língua/cultura em aprendizagem através de representações ou imagens estereotipadas. É papel do professor de língua levar em consideração esta realidade favorecendo assim ao seu aluno o reconhecimento e a reflexão de aspectos linguístico-culturais da língua em aprendizagem e os aspectos inerentes também a sua língua/cultura materna.

Portanto, neste projeto, focamos no ensino/aprendizagem da língua estrangeira não somente no conhecimento de sua estrutura linguística, mas também possibilitando, aos alunos participantes, a compreensão de elementos que integram a sua cultura. Nesse sentido, no "laboratório" que é a Extensão, através do nosso projeto, partimos da descoberta de fatores socioculturais inerentes à língua em aprendizagem (e à língua materna) através de uma perspectiva intercultural.

Para Zarate (1986, p. 62) "a aula de língua pode ser definida como o lugar em que as representações da cultura nacional estrangeira vêm à tona"2. Nesse sentido, ainda citando a autora, a aula de língua estrangeira pode favorecer uma tomada de consciência dos mecanismos da identidade individual e por um viés da confrontação com o outro, uma percepção de si se elabora. Portanto, a tomada de consciência da diversidade, em sala de aula, favorece, entre outros, a não generalização e o não julgamento das línguasculturas em presença. $\mathrm{O}$ enfoque de temas interessantes aos alunos permite uma maior participação, elemento indispensável na sala de aula.

Neste projeto, especificamente, o contato com alunos pluriculturais, exigiu, da professora em formação, Técnica e habilidade específicas, não somente na elaboração dos conteúdos e no tempo de uma aula, mas também adaptação dos conteúdos às realidades pluriculturais presentes na sala de aula. É o alunoprofessor em formação construindo sua base de conhecimento contemplando a atividade de ensinar línguas a partir de uma perspectiva socialmente situada (Johnson e Freeman (2001) APUD QUEVEDO-CAMARGO,2013, p.213).

Como sabemos, o ensino se tornou um trabalho especializado e complexo, uma atividade rigorosa, que exige, daqueles e daquelas que a exercem, a existência de um verdadeiro profissionalismo (TARDIF e LESSARD, 2014, p.9). Apesar dessas exigências, o aluno-professor em formação, através da prática da Extensão, fortalece suas bases no oficio de professorlibertando-se progressivamente de antigas inquietações (angústias) como a "obrigação" de preparar e administrar tudo o que está "prescrito" no manual, insegurança quanto à duração de uma aula e o conteúdo prescrito. Para SACRISTÁN E GOMEZ, os esquemas, ideias ou modelos de planejar uma atividade contextualizada como o ensino podem e deveriam servir para ordenar e diferenciar o espaço problemático concreto que constitui cada situação (2000, p. 276).

A prática, nos cursos de Extensão, leva o docente em formação a encontrar instrumentos para organizar, realizar e controlar a ação. Segundo MAIA [...] a articulação entre teoria e prática facilita a tomada de decisões de forma autônoma e consciente, induz à reflexão e a mudanças constantes de atitudes, formas de fazer e de se relacionar por parte dos futuros professores (MAIA, 2015, p. 18).

2La classe de langue peut être définie comme le lieu où les représentations de la culture nationale étrangère sont mises à jour. 


\section{Algumas considerações finais}

Neste trabalho, fizemos um "passeio" por alguns campos que integraram a construção da prática didático-pedagógica do professor em formação a partir do projeto de extensão Língua e cultura francesas para as comunidades acadêmica e externa. Pudemos rever fatores de cunho técnico como preparar e administrar o que está "prescrito" no manual do aluno, gerenciar o tempo/duração de uma aula, entre outros. Fizemos também uma reflexão sobre a percepção destes fatores pelo aluno-professor em formação e sua relação com uma concepção de linguagem que contemple a atividade de ensinar línguas a partir de uma perspectiva socialmente situada, com a adaptação dos conteúdos às realidades pluriculturais presentes na sala de aula, possibilitando a descoberta de fatores socioculturais inerentes à língua em aprendizagem (e à língua materna) através de uma perspectiva intercultural. Portanto, projetos de Extensão propiciam a união entre teoria e prática trazendo um empoderamento ao aluno-professor em formação, principalmente na confrontação com atividades, do ofício de professor, conhecidas por difíceis de serem realizadas. 


\section{Referências}

BRASIL. Ministério da Educação e Cultura. Conselho Nacional de Educação. Resolução CNE/CP 1/2002 de 18 de fevereiro de 2002. Institui Diretrizes Curriculares Nacionais para a Formação de Professores da Educação Básica, em superior, curso de licenciatura, de graduação plena. Diário Oficial da União, Brasília, 09 abr. 2002.

CHIANCA, R.M.S Interagir em língua estrangeira: um assunto sociocultural. Tradução: Elisa Nóbrega; Ingrid Farias Fechine Oliveira; Sandra Helena Gurgel Dantas de Medeiros. In: MOARA, Revista dos Cursos de Pós-Graduação em Letras da UFPA. Belém: Editora Universitária / UFPA, n.11, p. 1-164, jan./jun.,1999, p.65-84, 2006.

MARTINEZ, Pierre. Didática de línguas estrangeiras. Editora Parábola, 2008. Título original: La didactique des langues étrangères. Traduzido da 5a edição atualizada, de outubro de 2008. Presses universitaires de France, 1996.

DE CARLO, M. L’interculturel. Paris: CLE International, 1998.

MAIA, Angélica. Que currículo (trans)forma professores? Um debate sobre as possibilidades de formação docente no pibid identificadas por alunos de letras-inglês da ufpb. In: PEREIRA; M.ZC.; ALBINO, A.C.; DANTAS; V.X. (Orgs.). Políticas de currículo e formação: desafios contemporâneos. 1ed.João Pessoa: Editora da UFPB, 2015, v. 1, p. 102-120.

QUEVEDO-CAMARGO, Gladys. Gênero profissional professor de língua inglesa: qual a base do seu conhecimento? In: CALVO, Luciana C. Simoes ; EL KADRI, M.S. ; ORTENZI, Denise Grassano ; SILVA, K. (Orgs.) Reflexoes sobre o ensino de linguas e formacao de professores no Brasil: uma homenagem a Telma Gimenez. 1. ed. Campinas, SP.: Pontes Editores, 2013, p. 205-227

SACRISTÁN, J. Gimeno; PÉREZ GOMES, A. I. Compreender e transformar o ensino. 4. ed. Porto Alegre: ARTMED, 2000

TARDIF e LESSARD, O Ofício de professor (História, perspectivas e desafios internacionais. Editora Vozes 2014.

TARDIF, Maurice. Saberes profissionais dos professores e conhecimentos universitários: Elementos para uma epistemologia da prática profissional dos professores e suas consequências em relação à formação para o magistério. In: Revista Brasileira de Educação. São Paulo, n. 13, 2000, p.5-24.

ZARATE, G. Enseigner une culture étrangère. Paris: Hachette, 1986. 